\title{
La relevancia de la excusa en El Negro Francisco
}

\section{Estebana Matarrita}

Universidad de Costa Rica

La teoría de los presupuestos y, más recientemente, la llamada teoría de la relevancia, ofrecen instrumentos de análisis cada vez más eficaces para comprender los aspectos implícitos que se juegan en la comunicación y, por ende, en los textos literarios. Del mismo modo, estos elementos de pragmática general resultan operadores muy útiles para llevar a cabo los objetivos primordiales de la sociocrítica, los cuales resumo así:

1. Indagar en lo que tradicionalmente se ha considerado el estilo del texto, las huellas de una determinada coyuntura histórico-social.

2. Examinar los modos en que se deconstruyen en el texto las formas discursivas que le dieron origen.

3. Materializar la función significante, en el plano connotativo, de las formas de expresión en el relato. Es decir, desentrañar el sentido de la semiosis textual; para ello es imprescindible comprender el texto en la totalidad de la situación comunicativa que él constituye.

Por lo tanto, es necesario:

1. Un enfoque genético que dé cuenta de las diversas transformaciones que sufre la coyuntura histórico-social que está en la base, para invertir finalmente los fenómenos textuales específicos. 
2. Un análisis estilístico que muestre el trabajo de lenguaje y las prácticas que le son constitutivas.

3. Una perspectiva pragmática que permita abordar no solo el plano del enunciado sino también la toma de posesión del discurso por parte del sujeto, es decir, la emancipación. En otras palabras, esas condiciones de producción captadas en el concepto de enunciación y en el que se unen el código lingüístico y el código textual.

Estos aspectos servirán de punto de partida al análisis que propongo de la novela ElNegro Francisco, de AntonioZambrana' ${ }^{1}$. Se trata de un relato que cuenta la historia de una pareja de esclavos que nunca logra concretar su amor y que sufre diferente tipo de maltrato por parte de su amo. Al final, Francisco se suicida; Camila se vuelve loca hasta que muere y el amo, Carlos, se impone la pena de luchar contra la esclavitud para expiar su culpa.

Analizaremos el texto como un acto de lenguaje, es decir, como generador de una serie de relaciones interhumanas, de las cuales él es el marco institucional, la regla. Al igual que la lengua, y está hecho de ella, el texto será un juego, o mejor aun, las reglas de un juego, el juego del sentido. Ese sentido será buscado fundamentalmente en uno de los aspectos del acto de palabra: la enunciación.

Las marcas de este nivel no son explícitas y el texto nolas expone a la discusión, son formas implícitas, connotadas y, por ende, de un valor más berthesianamente literario. Se trata de leyes del discurso que imponen modos de producción y recepción al mismo tiempo.

Partiremos de dos leyes muy generales: a. la ley de la motivación, según la cual, existe un interés particular que mueve al locutor a

1. Zambrana (1846-1922) fue filósofo, jurista y poeta cubano, de orientación positivista. Luchó por la independencia de su país, fue fundador de la República, participó en la redacción de la primera Constitución de su patria y autorizó el primer decreto de abolición de la esclavitud que se dio en Cuba. A Costa Rica llegó en 1873 y fundó la Academia de Ciencias Sociales. Desempeñó diversos cargos públicos y desarrolló una obra fecunda en los diferentes campos de la cultura. 
hablar; en este caso, al productor del texto a escribir. Así, como no se habla por hablar, no se escribe por escribir. Esto debe entenderse como un imperativo ético, dentro de una deontología lingüística; y b. la ley de la gramaticalidad, según la cual, para cada categoría de acto de palabra, y el texto es un acto de palabra, existe una reglamentación particular. Estas leyes y su examen en el texto deben, en principio, conducirnos a identificar un modo o modos discursivos específicos y su correlativa normalidad.

Sobre estas leyes, en el examen del protocolo inaugural de la novela, se destacan los siguientes asuntos:

- ¿Por qué escribe el autor?

El prólogo contesta:

Para responder a una solicitud.

Para denunciar un crimen nacional.

Para borrar de la frente de Cuba una mancha ominosa.

- ¿Cuál es la forma discursiva seleccionada?

También el prólogo lo aclara:

Desde el punto de vista retórico: la narración (una novela).

Desde el punto de vista argumental: una historia de amor.

Desde el puntode vista sociocomunicativo: el discurso confesional.

Dentro de esta elección de formas discursivas, el discurso confesional es el marco englobante; pues, en un primer plano, el del enunciado, el texto no es otra cosa que la novelización de una confesión provocada por una historia de amor frustrado. En un segundo plano, el de la enunciación, la escritura misma del texto se propone como la expiación de una culpa, lo cual implica, al mismo tiempo, la confesión de la comisión de una falta. El discurso confesional, es una modalidad locutiva instituida dentro de dos prácticas sociales: la religiosa y la jurídica. No obstante, se articula de modo muy distinto en cada una de ellas. En la práctica jurídica es el delito su nudo conceptual y en la práctica religiosa es la noción de pecado quien la justifica. 
En resumen, la forma discursiva dominante que el texto selecciona es la de un discurso confesional, cuya normatividad está dictada por dos prácticas sociales: la jurídica y la religiosa. Esta situación genera un fenómeno de interdiscursividad sumamente conflictivo, cuyo antagonismo sólo se podrá resolver acudiendo a la ley de la motivación, es decir, definiendo la semiótica de su contenido semántico en crisis.

Pero volvamos al texto en cuestión: desde las notas introductorias, el prefacio del libro, el autor afirma que su intención es la de denunciar un crimen nacional por el solo hecho de ser miembro de esa comunidad. Aclara conjuntamente que adoptó en su interior "la resolución irrevocable de no ser cómplice de ello"2.

Un rápido análisis de algunos preconstruidos del texto citado nos indican las huellas de cierto discurso: - crimen, - resolución irrevocable, - cómplice.

Se hace evidente, pues, un discurso jurídico y, lo que es más, una figura o acto jurídico nítidamente delineado: la confesión.

Cuando se habla de complicidad, se presupone un delito y requerimiento consecuente de un proceso judicial. Tal y como se ha visto, el delito no es negado sino más bien confesado, y en esta misma figura la confesión, que representa una práctica ritual y discursiva, se imbrica en una simbiosis muy estrecha, otro calco discursivo. A este respecto, obsérvese el siguiente fragmento:

"Consagrar en la primera ocasión oportuna su alma a borrar de la frente de Cuba la mancha ominosa".

Los términos "consagrar", "sangre", "alma", "mancha", "frente" y otros más, vecinos de ese mismo fragmento, como "espíritu", "interior", "historia dolorosa", "tragedia", responden a un discurso religioso que viene a conjugarse con otro tipo de discurso en el entramado del texto.

2. Las citas textuales corresponden a la edición de 1953, de La Habana: Colección Los Zambrana. En adelante se indica entre paréntesis el número de página. 
Este discurso religioso desencadena, a su vez, un sistema semiótico tejido alrededor de una cierta noción de pecado, el pecado como mancha, la cual debe ser lavada.

De manera que el acto de producción textual es asimilado a un acto de ablución que comienza a generar significados encabalgados en dos discursos dominantes. Así,

\section{Desde lo jurídico}

crimen confesión retribución perdón
Desde lo religioso

pecado confesión penitencia absolución

De esta forma, la interdiscursividad del texto se inserta en el seno de prácticas rituales diversificadas, que representan otras tantas prácticas ideológicas.

Por esta razón la coincidencia de estos dos discursos no es aleatoria, es el resultado de una coyuntura precisa que se constituye en las posibilidades de producción del texto, posibilidades que no le son exteriores, sino más bien constitutivas. Así, por intermedio de sus calcos discursivos, la novela traza con nitidez una formación social dominada por un modo de producción feudal, identificado como "hacienda", y en el caso particular del texto que nos ocupa, como una hacienda de caña con un ingenio.

Esta es la base económica del gobierno organizado por la aristocracia española colonial en Cuba. Tanto el gobierno como la base económica que lo alimenta, están apoyados y legitimados por la iglesia como Aparato Ideológico del Estado dominante.

Se trata de una formación social esclavista, cuyos dos aparatos principales, uno represivo y otro ideológico, mantienen el statu quo y reproducen las relaciones sociales de producción.

Si bien la novela esboza una crítica al sistema descrito, la forma confesional del texto transforma la incipiente crítica en una justificación que busca reivindicar y neutralizar todo probable cuestionamiento. 
El texto parece ensayar, de este modo, una especie de autoexamen y juego dialógico en el que la conciencia se desdobla en emisor y destinatario, generando alternadamente la pregunta y la respuesta. El texto delata y confiesa, pero también excusa y, con ello, reivindica una falta, una infracción que sólo se terminará de perfilar en el margen mismo del proceso enunciativo.

El final del relato cambia abruptamente de espacio, el culpable, convertido en penitente por su propia voluntad, es ahora un militante de la lucha abolicionista en Estados Unidos. El cambio de espacio en el epílogo confesional del relato nos of rece ya la clave, la explicación del gesto crítico que matiza el texto.

La general tendenciosidad ideológica de la novela dominada por el discurso religioso, es puesta en jaque por este comportamiento cuestionador, que se refugia en el cauce de un discurso jurídico. Este discurso jurídico es el indicio de formas discursivas nuevas que corresponden a la emergencia de una formación social también nueva: la forma capitalista, representada aquí por la influencia de Estados Unidos.

Por otra parte, es de notar que el discurso jurídico conlleva el desplazamiento de lo religioso a una dominante ético-económica, donde la noción de libertad, correlativa a esa dominante, implica también una igualdad jurídica.

Ahora, la emergencia de este discurso jurídico en el texto se explica en un movimiento independentista de formación de estados, que es el caso de Cuba en la coyuntura histórica de este relato.

Confrontado el productor del texto ante la lucha cubana, la lee a través del filtro dominante de la fe cristiana, discurso y práctica religiosa, y las sagradas escrituras. Del Antiguo Testamento extrae prácticas jurídicas arcaicas de distribución de la justicia. De ahí la presencia implícita de los arquetipos que articulan macroscópicamente el universo textual. Estos arquetipos son: la Ley del Talión y la Mancha Original (entiéndase el origen de la mancha), es decir, el pecado original.

Ambos arquetipos son interdependientes. Según Paul Ricoeur, el simbolismo más arcaico que podemos tomar como punto de partida 
es el del mal concebido como suciedad o mancha, es decir, como tacha que contamina desde afuera. Este arquetipo pertenece a la mentalidad de los pueblos primitivos y descansa en un principio ético-mágico tabuístico, del que se deriva un universo semántico global, caracterizado por las siguientes marcas: a. da lugares a los ritos de purificación (catarsis); b. trae, como consecuencia, llevar el hecho del pecado por derroteros de "automatismo" (costumbre), como algo irracional, impuesto desde afuera, donde no hay opción para la libertad de la persona; y c. la dimensión comunitaria como cooperación en el mal se extiende solamente por mecanismos de comunicación exterior. De ahí que, en la noción y en la vivencia externa de la culpabilidad, se conjuguen los siguientes residuos tabuísticos:

- Violencia mecánica (no asumida responsablemente) de una norma que se expresa en conductas ritualistas, legalistas y con ciertos ritos obsesivo-compulsivos.

- $\quad$ Miedo frente al castigo divino, que se descargaría inmediatamente después de haber pecado el hombre; conexión entre pecado y mal físico.

- Víctima expiatoria, se desprende como consecuencia de lo anterior. Se cae en la necesidad de una víctima expiatoria (desde Job no podemos hablar de retribución automática).

- Comprensión del futuro escatológico, miedo al castigo eterno; presentación de un Dios justiciero y vengativo; comprensión de la vida como continua reparación de pecados propios y ajenos.

- $\quad$ Concepto de pecado como impureza ritual, sobre todo en el aspecto de la sexualidad, relaciones conyugales, poluciones, entre otras, y la relación confesión-comunión como un rito purificativo para acercase a un tabú.

- Hincapié en ciertos temas: la virtud de la religión. 


\section{Il texto como rito de purificación}

\section{La tacha que contamina desde afuera}

Según este sistema de representación, el mal al que se refiere el texto (la esclavitud) no es endémico, Cuba lo adquirió de España. De aquí la significación de la referencia al movimiento revolucionario de independencia cubana:

Que no se ocupen tanto de combatir la dominación española, de obtener esta o aquella forma de gobierno, esta o aquella libertad, esta o aquella garantía. Que se ocupen sobre todo de los negros. No de no ser explotados, que se preocupen de no explotar. Terrible es la esclavitud que se sufre: pero más tremenda todavía la que se impone. Ustedes dicen:

¡Ah, si los cubanos no fueran esclavos! ¡Ah, si no los tuvieran digo yo! (165).

\section{Esclavitud de segundo grado}

Los esclavistas son esclavos de otros. El tema no es hombre blanco/hombre negro, sino que el eje conceptual se refiere, sobre todo, a la libertad.

En el otro plano, la posición de la clase del escritor en relación con el texto. Él, como manifestación de la dominante, se apresta a defender en términos generales su ideología $\mathrm{y}$, a mantenerla en detrimento de las clases marginadas ${ }^{3}$.

Dos niveles de análisis unidos por el sema dominante la libertad: 1. Cuba en relación con España; y 2. las dos clases sociales en Cuba: los amos y los esclavos.

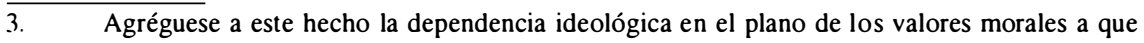
están sujetos los esclavos. 
Por otra parte, además de no ser endógena, la esclavitud se define como costumbre, por lo tanto, tampoco es responsabilidad del estado en cuanto al uso, porque como él no lo da como norma, la costumbre no aparece como oficial. Es una norma en ausencia de normas. Es espontánea, es lo no consciente de la ideología. Costumbre es fiel sinónimo de prácticas ideológicas. Según la obra, el pecado viene de afuera. Los cubanos heredaron la costumbre de sus colonizadores (heredaron un automatismo). Lo no consciente de la ideología.

De ahí que vista esa costumbre como pecado, se impone un rito de purificación, es decir, una catarsis. El productor del texto lo confiesa (la producción de ese texto es una oportunidad de purificarse, es un proceso catártico).

Las dos líneas discursivas, la jurídica y la religiosa, se imbrican finalmente en una sola figura que es la de la confesión (figura jurídica y religiosa). Desde el punto de vista religioso, ella constituye el punto culminante del ritual de purificación. Está ubicado al final del texto; la confesión del productor concluye haciendo confesar al mismo tiempo al protagonista imputado (Carlos Orellana), quien se ha entregado a las luchas abolicionistas en Estados Unidos.

Dos sombras coléricas nos perseguían entonces. Ahora me figuro que me miran piadosamente. Si el alma de un hombre puede lavarse en la tierra de semejante mancha de abominaciones, la mía se lavará, te lo juro (164).

El estado y el individuo quedan igualmente liberados. Carlos como individuo queda liberado porque el mal le llegó desde afuera. El mal no es endémico. Está en la metrópoli, en la otra esfera opresora y Carlos paga su culpa con la misma moneda: se niega el amor y lucha por la abolición de la esclavitud. La violación a la norma (los Derechos Humanos) es excusable, no se es responsable porque ha sido impuesta desde afuera. Ni siquiera en esta situación hubo libertad. Ni en negar la libertad a los otros. 
La culpa existe porque hay miedo al castigo divino. Cuando se dieron cuenta de que también eran esclavos, en tanto que la independencia les era negada, sometieron su conciencia, sus costumbres (su vida pasada y presente) a un examen que tratara de explicar la causa de ese castigo (privación de la libertad, sometiendo al régimen colonial). Los cubanos descubren la causa, ellos mismos habían cometido el mismo pecado social.

\section{La víctima expiatoria}

En este plano es la misma España, porque ella les enseñó a pecar. La conexión entre el pecado y el mal físico es clara, se dice: "sufrir en carne propia". Es un mal físico tal, que se habla de una mancha en la frente.

\section{Comprensión del futuro escatológico}

Si existe miedo al castigo es porque existe la representación de un Dios justiciero y vengativo. Vengativo en tanto que establece procesos de retribución que, en este caso, son equivalentes a su propio peso; es decir, la metáfora de la balanza también conocida como Ley del Talión, "ojo por ojo, diente por diente": privación de libertades frente a privación de libertades.

Y como este Dios es justiciero, del pecado pasamos al acto delictivo y un proceso penal se impone con todas sus consecuencias. Acusación, prueba, defensa, confesión y sentencia. En sus Ensayos filosóficos, John Austin tiene un capítulo titulado «Alegato en pro de las excusas» ${ }^{4}$. Allí el autor afirma que se ofrecen excusas cuando alguien es acusado de haber hecho algo mal, incorrecto, inaceptable o adverso, y tratará, con ellas, de defender su conducta.

4. John Austin, Ensayosfilosóficicos (Madrid: Revista de Occidente, 1975). 
Habiendo señalado el productor del texto que su propósito era acusar, denunciar un crimen, el desarrollo textual, además de denunciarlo, lo excusa aduciendo que el imputado - Cuba - se encontraba bajo la influencia de otro -España-. Estamos, pues, nuevamente ante el problema de la responsabilidad y la libertad.

Según Austin, para lo que más a menudo damos excusas es para eludir la responsabilidad. Y señala el autor que en el estudio de las excusas, una de las fuentes más ricas, además del diccionario y la Psicología, es el Derecho. Él proporciona una inmensa miscelánea de casos adversos y una útil lista de alegatos admitidos junto con una buena cantidad de análisis agudos de ambos.

En el campo de las excusas, el derecho consuetudinario y, en particular, el derecho judicial son los almacenes más ricos, más exhaustivos y más flexibles. En los juicios, eso sí, debe llegarse a una decisión en blanco y negro; en favor del fiscal o del defensor, y la acusación y los alegatos se someten a una u otra de las figuras y procedimientos que han llegado a ser aceptados por los tribunales. Así, el producto del texto resume simbióticamente los dos papeles esenciales del litigio: fiscalía y defensa; y, en este sentido, el texto es perfectamente dialógico.

Sin embargo, siguiendo la gramaticalidad impuesta por la práctica discursiva correspondiente, hay resolutoria: el diálogo se resuelve en favor del imputado, habida cuenta de la existencia de un atenuante: la confesión.

Existe una separación entre el discurso jurídico y el religioso con respecto al protagonista, porque desde el punto de vista religioso él no queda absuelto; la ley divina no es tan magnánima: Carlos queda condenado a no amar ("ojo por ojo"). En relación con Cuba, por extrapolación, pareciera dejar el texto en suspenso la posibilidad de correr la misma suerte, es decir, de ser víctima del talión. Con este planteamiento también se infiere que en el texto, Dios es fundamentalmente vengativo al aplicar la justicia del talión.

La finalidad del proceso penal es la búsqueda de la verdad para impartir justicia y en esta novela la justicia se desborda en un arriba y 
un abajo: una justicia terrena (cuyo marco es la juricidad) y una justicia divina (a la que se apela porintermedio de la religión). En ambos casos, y según el texto, prima el principio iustitia suum cuique distribuit y en el asunto que nos incumbe sería: al esclavo su libertad; a Cuba su independencia.

\section{Conclusión}

El proyecto de elaborar una tesis abolicionista ha quedado obnubilado al hacerlo pasar por los códigos de transformación seleccionados en el texto. Al confesar el pecado y el delito de una práctica esclavista y definida esta como costumbre y como mancha que altera desde afuera un estado de pureza, la comunidad es reivindicada por la excusa y se transfiere la responsabilidad a una instancia político-social definida como la metrópoli, España.

Queda eliminado ya el problema del negro versus el blanco y se plantea un nuevo conflicto, el de Cuba frente a España. Es el viejo antagonismo entre dominados y dominantes; pero no de los dominados en Cuba por los cubanos, sino el de los dominados por los españoles. Es decir, en una esfera política, la extrapolación adecuada sería la siguiente: la colonia frente a la metrópoli. Esta situación la hemos demostrado a lo largo del análisis: la función de los discursos jurídico y religioso. Lavada la mancha, Cuba se dispone, libre de culpas, a llevar a cabo su destino de liberación, el último capítulo de la independencia americana frente a España.

Desde el punto de vista de la semiosis del texto, lo ocurrido en su proceso de generación se puede definir en términos de una inversión operada en el paso del nivel explícito al implícito. Al pasar al segundo nivel, el de la connotación, los valores propuestos por el primer sistema fueron invertidos por el segundo. De ahí que el texto resulta ser, finalmente, una apología de la clase en el poder, la burguesía agrícola cubana, cuyos valores, eventualmente condenados, aparecen luego como los valores que mueven las acciones de los esclavos y, por 
ello mismo, la marginalidad de estos parece ser únicamente institucional, pues el negro vive participando de una cierta atracción al centro, comparte con ese centro el ideograma moral: honradez, virginidad, lealtad, honor, respeto, entre otros valores. Al respecto revísese el siguiente segmento:

Y al inclinarse hacia la raza negra no pudo menos de fijar su mirada en la figura moral de aquel hombre que era su tipo más hermoso, que era tan fuerte, tan heroico y tan altivo que llevaba la servidumbre con la misma dignidad con que se puede llevar una corona y que, por el amor de su raza, acababa de desafiar una muerte horrorosa y repugnante; allí, a su lado, estaría ella de seguro más protegida que por la desdeñosa piedad de los blancos (28).

Obsérvese que los valores destacados y preconizados por el negro son los mismos de la clase dominante; esta contradicción social solo puede resolverse de dos maneras: con una separación física radical, la muerte, el suicidio de Francisco; o con una separación social absoluta, la locura en el caso de Camila.

Esta legitimidad que los mismos dominados confieren a las relaciones de dominación y opresión está vehiculada, por una parte, en la institucionalidad que la ley otorga a la práctica esclavista y, por otra, por unas categorías mentales modeladas por la religión. Contra aquellas se puede luchar, la libertad física, por ejemplo, se puede comprar:

Se ocuparían de reunir, a fuerza de economía, alguna pequeña suma, comprando con ella su libertad, para que sus hijos no fueran esclavos y harían del amor, el trabajo y la virtud los dioses tutelares de su familia y de su choza (65).

Pero frente a la interiorización de las relaciones de dominación, los personajes no tienen salida: "No Francisco, no soy digna", le dice Camila a su amado, porque ha sido violada por el amo y ha perdido su virginidad. 
Queda, pues, en evidencia que la fuerza del poder de opresión, de dominación, no es ciertamente la fuerza violenta, sino por el contrario, un consentimiento de los dominados por su dominación. Atenidos a este principio, se explica que, en Cuba, las clases que cstarían al frente de la guerra de liberación no serán estas marcadas por cl texto, la burguesía agrícola, sino otras: la pequeña burguesía, los pequeños propietarios, los profesionales, los tabaqueros, los campesinos pobres, la incipiente clase obrera en general. Eso, más la vecindad y el crecimiento de Estados Unidos, hacen de la guerra de independencia cubana un capítulo diferente en la liberación hispanoamericana.

Hemos comprobado, mediante el análisis de la interdiscursividad del texto, que El Negro Francisco no es realmente un relato abolicionista, sino una excusa, un acto de catarsis que, condenando errores sociales cometidos, intenta alcanzar el grado de pureza y dignidad exigido como requisito previo a la lucha por la libertad. Todo ello, gracias a una propuesta sociocrítica. 